\title{
REVIEW
}

\section{The necessity of regional DOHaD centers based on programming/imprinting and embedding-like phenomena}

\author{
Viktor Ivanovitch Goudochnikov
}

\begin{abstract}
A mini-review is presented for the evidence of growth-inhibitory effects of several psychoneurotropic drugs and glucocorticoids on developing animals and humans, together with our own data obtained in experimental models, as well as in epidemiologic studies confirming female predominance in morbidity caused by affective disorders and in consumption of some psychoneurotropic drugs. The emerging concepts of pharmacotoxicologic programming/imprinting and embedding are discussed, justifying the necessity of regional DOHaD centers.
\end{abstract}

Keywords: anticonvulsive drugs, benzodiazepines, glucocorticoids, ontogeny

\section{Introduction}

At present the paradigm of Developmental Origins of Health and Disease (DOHaD) may be considered as well established worldwide, ${ }^{[1]}$ and the role of endogenous and exogenous glucocorticoids (GC) in programming/imprinting phenomena is confirmed in a number of experimental and clinical studies. ${ }^{[2]}$ However, not only GC are used as pharmacotherapeutic agents in pregnancy, perinatal period and early postnatal ontogeny. In fact, psychoneurotropic (PNT) drugs constitute one of the categories with predominant use during human development, both pre- and postnatally. ${ }^{[3]}$ In addition, at least some drugs of abuse and environmental toxicants may also affect body and brain growth during development.

Therefore, the presented mini-review aimed at discussing the evidence available on the effects of PNT drugs and GC on developing humans and animals, focusing on the alterations of body and organ growth, including our own data obtained in experimental models on developing rats.

Received: April 1, 2019; Accepted: April 24, 2019; Published: April 28, 2019

* Correspondence to: Viktor Ivanovitch Goudochnikov, Council of International Society for DOHaD, Rua Matoso Camara 73, Bairro Dores, CEP 97050-500, Santa Maria - RS, Brazil; Email: victorig40@ hotmail.com

Citation: Goudochnikov VI. The necessity of regional DOHaD centers based on programming/imprinting and embedding-like phenomena. Adv Health behaviour, 2019, 2(1) 30-33.

Copyright: (c) 2019 Viktor Ivanovitch Goudochnikov. This is an open access article distributed under the terms of the Creative Commons Attribution License, which permits unrestricted use, distribution, and reproduction in any medium, provided the original author and source are credited.

\section{Enhanced vulnerability of developing ma- mmals to drugs and environmental agents}

On our opinion, the capacity to cause the programming/imprinting phenomena is not confined to exogenous GC. In fact, if to consider only the ability to alter body and organ growth, several anticonvulsive drugs and benzodiazepines are able to cause intrauterine growth restriction (IUGR), low birth weight and diminished head circumference or retarded brain growth. ${ }^{[3-7]}$ This was already proved for phenobarbital, phenytoin and carbamazepine, as well as for diazepam and some other benzodiazepines, both in animals, ${ }^{[8-14]}$ and in humans. ${ }^{[15,16]}$ From the drugs of abuse, especially cocaine and amphetamines are the first to be suspected for provoking IUGR, low birth weight and diminished head circumference. Finally, there is some evidence on growthinhibitory actions of polychlorinated biphenyls (PCB) in critical periods of human development, ${ }^{[17]}$ probably due to their capacity to interfere with effects of thyroid hormones. ${ }^{[18]}$

There are several explanations for higher vulnerability of central nervous system (CNS) in developing mammals to adverse effects of PNT drugs. ${ }^{[19,20]}$ One of them considers lower activity of hepatic metabolism of xenobiotics in perinatal period, as well as higher permeability of immature blood-brain barrier to PNT agents. ${ }^{[21,22]}$ However, the main factor explaining this peculiarity of developing mammals appears to be high liposolubility of PNT drugs and corticosteroids that facilitates their passage both through placenta and blood-brain barrier. ${ }^{[22,23]}$

On the other hand, it is important that PNT drugs interact with hormones. For example, phenobarbital in- 
teracts with dexamethasone in regulation of alpha1-acid glycoprotein production by hepatocytes; ${ }^{[24]}$ in addition, it interferes with hepatic metabolism of sex steroids, resulting in alterations of growth hormone secretion, [25] whereas benzodiazepines provoke the diminution of the activity of hypothalamo-pituitary-adrenal axis, ${ }^{[26]}$ and on the contrary, phenytoin is capable to enhance corticosterone secretion in mice. ${ }^{[27]}$

\section{Our own data on the effects of glucocorti- coids and psychoneurotropic drugs on de- veloping animals}

The involvement of the author in this important topic began already during the decade of nineties in the last century, when it was possible to observe greater inhibition of DNA and total protein biosynthetic rates by dexamethasone in pituitary cell cultures of neonatal rats, as compared to prepubertal and adult animals. ${ }^{[28]}$ Thereafter it became possible to show sustained retardation of body and organ growth by dexamethasone administered to neonatal rats. ${ }^{[29]}$

Later on, we compared the effects of glucocorticoids and some PNT drugs on body and organ growth in rats. We have demonstrated growth-inhibitory actions of phenytoin, phenobarbital and diazepam administered neonatally to rats or later in postnatal ontogeny, however, in general, these effects were less intense and not so consistent, as compared to those of GC. ${ }^{[30]}$

One of the most interesting peculiarities discovered was growth-inhibitory action of diazepam on pituitary gland, but it is important to note that previously similar action was demonstrated already both in vivo and in vitro by another researchers. ${ }^{[31,32]}$

Finally, we were able to show the capacity of GC and some PNT drugs to diminish the extent of hydration in the organs evaluated, ${ }^{[33]}$ and again the effects of GC were much more intense and consistent, as compared to PNT drugs. After Selye et al. ${ }^{[34]}$ we interpreted these data as one of possible mechanisms of growth inhibition provoked by these drugs, as related to cell shrinkage and apoptosis, ${ }^{[35]}$ contrary to cell swelling in growth stimulation. ${ }^{[36]}$

\section{Pharmacotoxicologic programming / im- printing and embedding}

The term and concept of pharmacological programming was introduced by British obstetrician Helen Bayliss and her colleagues, when discussing the effects of atenolol and other beta-blockers in pregnancy. ${ }^{[37]}$ More recently, we have expanded it to pharmacotoxi- cologic programming / imprinting and embedding. ${ }^{[38,39]}$ What is the difference, as related to original concept? Primarily, not only beneficial, pharmacotherapeutic action is included, but also adverse, unfavorable and potentially toxic effects are considered. In addition, the embedding phenomena are intended as chronic, cumulative and occurring predominantly in early postnatal ontogeny, as compared to programming/imprinting events, characteristic for relatively acute and subacute influence in prenatal and perinatal periods. Of course, there may be some overlapping in these phenomena, depending on pharmacotherapeutic regimens utilized.

Why is it so important to elaborate and use these concepts? Surely, nobody is interested in promoting steroid phobia or some similar problems. However, we find as highly unwise not to note obvious adverse side effects of GC and at least some PNT drugs. Moreover, we suppose to use experimental models on laboratory animals to find out the ways of diminishing adverse side effects and consequently, pharmacotoxicologic programming / imprinting and embedding, e.g. by the use of adjunct antioxidants ${ }^{[40]}$ or some antistress agents like melatonin. ${ }^{[41,42]}$

At present it is well established that epilepsy, depressive illness and other neuropsychiatric disorders, if not treated in pregnancy, are dangerous per se in potentially provoking adverse perinatal outcomes, ${ }^{[43,44]}$ therefore it is not a question, to use or not to use PNT drugs during gestation. ${ }^{[14,21]}$ Since our participation in Expert Committee on Psychopharmacology, associated with the Secretariat of Health Affairs in the Government of Brazilian state of Rio Grande do Sul (RS), ${ }^{[46]}$ we were already interested in more detailed studies of PNT drugs and neuropsychiatric disorders. As a matter of fact, we were able at first to show clear-cut gender differences, with female predominance in the consumption of at least, benzodiazepines and antidepressants in North-Western region of the state of $\mathrm{RS}^{[47]}$ and thereafter, in morbidity associated with affective disorders in three Brazilian states of Southern region. In addition, in a pilot study we have obtained preliminary data on substantial consumption of PNT drugs in women younger than 40 year old, what allowed us to suggest higher risk of pharmacotoxicologic programming / imprinting in this fertile female subpopulation. ${ }^{[38]}$ Characteristically, the peak of morbidity caused by affective disorders takes place also in the intermediate age categories.

\section{Conclusion}

Surely, we are aware of the difficulties in organizing long-term prospective studies of drug surveillance in experimental models on rodents up to adult state and espe- 
cially, till the senescence. ${ }^{[48]}$ Really, the results of such studies are quite rare in world literature ${ }^{[49]}$.

Even the retrospective epidemiologic studies need the eminent scientists like David Barker who was lucky enough to discover the archives in Hertfordshire (UK) of the beginning $20^{t h}$ century $^{[1]}$. Therefore, we would like to propose the necessity of organizing regional $\mathrm{DOHaD}$ centers that could be responsible for performing epidemiologic and experimental investigations in the framework of $\mathrm{DOHaD}$. Obviously enough, the principal goal remains the same: to promote better health, particularly in the groups of pregnant and lactating women, children and the elderly.

\section{References}

[1] Gluckman PD, Hanson MA, Buklijas T. A conceptual framework for the developmental origins of health and disease. Journal of Developmental Origins of Health and Disease, 2010, 1(1): 6-18. https://doi.org/10.1017/S2040174409990171

[2] Harris A and Seckl J. Glucocorticoids, prenatal stress and the programming of disease. Hormones and Behavior, 2011, 59(3): 279-289. https://doi.org/10.1016/j.yhbeh.2010.06.007

[3] Costa LG, Steardo L and Cuomo V. Structural effects and neurofunctional sequelae of developmental exposure to psychotherapeutic drugs: Experimental and clinical aspects. Pharmacological Reviews, 2004, 56(1): 103-147. https://doi.org/10.1124/pr.56.1.5

[4] Thompson BL, Levitt P and Stanwood GD. Prenatal exposure to drugs: Effects on brain development and implications for policy and education. Nature Reviews Neuroscience, 2009, 10(4): 303-312. https://doi.org/10.1038/nrn2598

[5] Williams JHG and Ross L. Consequences of prenatal toxin exposure for mental health in children and adolescents: a systematic review. European Child and Adolescent Psychiatry, 2007, 16(4): 243-253. https://doi.org/10.1007/ s00787-006-0596-610.1007/s00787-006-0596-6

[6] Dodson WE. Deleterious effects of drugs on the developing nervous system. Clinics in Perinatology, 1989, 16(2): 339360 .

https://doi.org/10.1016/S0095-5108(18)30636-5

[7] Mantovani A and Calamandrei G. Delayed developmental effects following prenatal exposure to drugs. Current Pharmaceutical Design, 2001, 7(9): 859-880. https://doi.org/10.2174/1381612013397717

[8] Schain RJ and Watanabe K. Origin of brain growth retardation in young rats treated with phenobarbital. Experimental Neurology, 1976, 50(3): 806-809. https://doi.org/10.1016/0014-4886(76)90046-7

[9] Diaz J, Schain RJ and Bailey BG. Phenobarbital-induced brain growth retardation in artificially reared rat pups. Biology of Neonate, 1977, 32(1-2): 77-82. https://doi.org/10.1159/000240998
[10] Gupta C, Sonawane BR, Yaffe SJ, et al. Phenobarbital exposure in utero: Alterations on female reproductive function in rats. Science, 1980, 208(4443): 508-510. https://doi.org/10.1126/science.7367874

[11] Patsalos PN and Wiggins RC. Brain maturation following administration of phenobarbital, phenytoin, and sodium valproate to developing rats or to their dams: Effects on synthesis of brain myelin and other subcellular membrane proteins. Journal of Neurochemistry, 1982, 39(4): 915-923. https://doi.org/10.1111/j.1471-4159.1982.tb11477.x

[12] Diaz J. Disruption of the brain growth spurt in adolescent rats by chronic phenobarbital administration. Experimental Neurology, 1983, 79(2): 550-563. https://doi.org/10.1016/0014-4886(83)90233-9

[13] Vasconcelos AP, Boyet S and Nehlig A. Consequences of chronic phenobarbital treatment on local cerebral glucose utilization in the developing rat. Developmental Brain Research, 1990, 53(2): 168-178. https://doi.org/10.1016/0165-3806(90)90003-H

[14] Vorhees CV. Fetal anticonvulsant syndrome in rats: Doseand period-response relationships of prenatal diphenylhydantoin, trimethadione and phenobarbital exposure on the structural and functional development of the offspring. Journal of Pharmacology and Experimental Therapeutics, 1983, 227(2): 274-287.

[15] Van der Pol MC, Hadders-Algra M, Huisjes HJ, et al. Antiepileptic medication in pregnancy: Late effects on the children's central nervous system development. American Journal of Obstetrics and Gynecology, 1991, 164(1): 121128. https://doi.org/10.1016/0002-9378(91)90640-D

[16] Dessens AB, Cohen-Kettenis PT, Mellenbergh GJ, et al. Association of prenatal phenobarbital and phenytoin exposure with small head size at birth and with learning problems. Acta Paediatrica, 2000, 89(5): 533-541. https://doi.org/10.1111/j.1651-2227.2000.tb00333.x

[17] Zala SM and Penn DJ. Abnormal behaviours induced by chemical pollution: A review of the evidence and new challenges. Animal Behaviour, 2004, 68(4): 649-664. https://doi.org/10.1016/j.anbehav.2004.01.005

[18] Goudochnikov VI. Role of thyroid hormones and iodine consumption in the ontopathogeny of various diseases: Focus on interactions with glucocorticoids and some endocrine disruptors. Clinical and Experimental Thyroidology, Moscow, Russian, 2016, 12(1): 16-21. https://doi.org/10.14341/ket2016116-21

[19] Schettler T. Toxic threats to neurologic development of children. Environmental Health Perspectives, 2001, 109(suppl.6): 813-816. https://doi.org/10.1289/ehp. 01109s681310.1289/ehp.01109s6813

[20] Rodier PM. Environmental causes of central nervous system maldevelopment. Pediatrics, 2004, 113(4): 1076-1083.

[21] Hill LM and Kleinberg F. Effects of drugs and chemicals on the fetus and newborn (second of two parts). Mayo Clinic Proceedings, 1984, 59(11): 755-765. https://doi.org/10.1016/S0025-6196(12)65586-4

[22] Dorman DC, Allen SL, Byczkowski JZ, et al. Methods to identify and characterize developmental neurotoxicity for human health risk assessment. III. Pharmacokinetic and 
pharmacodynamics considerations. Environmental Health Perspectives, 2001, 109(Suppl.1): 101-111.

https://doi.org/10.1289/ehp.

01109s110110.1289/ehp.01109s1101

[23] Simar MR. Perinatal exposure to CNS-active medications: neurodevelopmental risks. CNS Drugs, 1999, 12(6): 451470.

https://doi.org/10.2165/00023210-199912060-00004

[24] Fournier T, Mejdoubi N, Monnet D, et al. Phenobarbital induction of alpha1-acid glycoprotein in primary rat hepatocyte cultures. Hepatology, 1994, 20(6): 1584-1588. https://doi.org/10.1002/hep.1840200630

[25] Agrawal AK, Pampori NA and Shapiro BH. Neonatal phenobarbital-induced defects in age- and sex-specific growth hormone profiles regulating monooxygenases. American Journal of Physiology, 1995, 268(3): E439E445.

https://doi.org/10.1152/ajpendo.1995.268.3.

E43910.1152/ajpendo.1995.268.3.E439

[26] Wilson MA, Biscardi R, Smith MD, et al. Effects of benzodiazepine agonist exposure on corticotropin-releasing factor content and hormonal stress responses: Divergent responses in male and ovariectomized female rats. Journal of Pharmacology and Experimental Therapeutics, 1996, 278(3): 10731082.

[27] Hirai M and Ichikawa M. Changes in serum glucocorticoid levels and thymic atrophy induced by phenytoin administration in mice. Toxicology Letters, 1991, 56(1-2): 1-6. https://doi.org/10.1016/0378-4274(91)90083-I

[28] Gudoshnikov VI, Fedotov VP. The heightened sensitivity of hypophyseal cells of neonatal rats to corticosteroids. Neuroscience and Behavioral Physiology, 1993, 23(2): 107-111. https://doi.org/10.1007/BF01189104

[29] Goudochnikov VI. Pathogeny of glucocorticoid-induced growth retardation evaluated in experimental studies using laboratory animals and cell cultures as the models. NewsLab (Sao Paulo), Portuguese, 1997, 22: 90-100.

[30] Goudochnikov VI, Weber C, Silva CEJ, et al. The absence of diazepam interactions with inhibitory corticoid effects on body and target organ growth in young rats. Revista Contexto Saude (Ijui), Portuguese, 2003, 2(4): 103-104.

[31] Pawlikowski M, Stepien H, Mroz-Wasilewska Z, et al. Effects of diazepam on cell proliferation in cerebral cortex, anterior pituitary and thymus of developing rats. Life Sciences, 1987, 40(11): 1131-1135. https://doi.org/10.1016/0024-3205(87)90577-7

[32] Kunert-Radek J, Stepien H and Pawlikowski M. Inhibition of rat pituitary tumor cell proliferation by benzodiazepines in vitro. Neuroendocrinology, 1994, 59(1): 92-96. https://doi.org/10.1159/000126644

[33] Goudochnikov VI and Weber C. Combined action of glucocorticoid and benzodiazepine on water content in target organs of rats. Revista Brasileira de Ciencias Farmaceuticas, 2005, 41: 231.

[34] Selye H, Prioreschi P and Jean P. Water fixation as the ultimate cause of tissue growth. Growth, 1959, 23: 169-187.

[35] Schliess F and Haussinger D. The cellular hydration state: a critical determinant for cell death and survival. Biological Chemistry, 2002, 383(3-4): 577-583. https://doi.org/10.1515/BC.2002.059
[36] Haussinger D. The role of cellular hydration in the regulation of cell function. Biochemical Journal, 1996, 313(3): 697-710.

https://doi.org/10.1042/bj3130697

[37] Bayliss H, Churchill D, Beevers M, et al. Anti-hypertensive drugs in pregnancy and fetal growth: evidence for "pharmacological programming" in the first trimester? Hypertension in Pregnancy, 2002, 21(2): 161-174. https://doi.org/10.1081/PRG-120013785

[38] Goudochnikov VI and Petersen R. Gender differences in psychotropic drug consumption may indicate enhanced risk of pharmacotoxicologic programming in perinatal period. Journal of Developmental Origins of Health and Disease, 2009, 1: S332-S333.

[39] Goudochnikov VI. Emerging terms and concepts of pharmacotoxicologic programming / imprinting and embedding, as related to the ontopathogeny of respiratory and other disorders. EC Pulmonology and Respiratory Medicine, 2018, 7(6): 413-415.

[40] Prokhorov LY and Goudochnikov VI. Role of glucocorticoids and stress in bioregulation of redox homeostasis in development and aging. Clinical Gerontology (Moscow, Russian), 2015, 21(11-12): 101-102.

[41] Goudochnikov VI and Prokhorov LY. Ontogenetic role of somatolactogens and related peptides as antistress hormones. Gerontologiya (Moscow), 2014, 2(2): 143-156.

[42] Prokhorov LY and Goudochnikov VI. Ontogenetic role of melatonin and neuroactive steroids as antistress hormones. Gerontologiya (Moscow), 2014, 2(2): 157-170.

[43] Mazaira S. Effects of psychiatric drugs on the fetus and newborn: Consequences of the treatment of psychiatric disorders during pregnancy and lactation. Vertex (Buenos Aires), Spanish, 2005, 16(59): 35-42.

[44] Bonari L, Pinto N, Ahn E, et al. Perinatal risks of untreated depression during pregnancy. Canadian Journal of Psychiatry, 2004, 49(11): 726-735. https://doi.org/10.1177/070674370404901103

[45] Sharma RR. Pregnancy, epilepsy and pharmacotherapy. Journal of Postgraduate Medicine, 1987, 33(4): 163-177.

[46] Camargo GN, Hirdes A and Goudochnikov VI. Expert committee on psychopharmacology: An ongoing experience in Brazil. International Journal of Psychosocial Rehabilitation, 2004, 9: 5-9.

[47] Goudochnikov VI. Gender differences in consumption of benzodiazepines by human population and in their effects on mice and rats. World Journal of Biological Psychiatry, 2007, 8: 200

[48] Goudochnikov VI. Pharmacoepidemiology and drug surveillance in collective health], in Coletanea da Saude / Saude Coletiva: Dialogos Contemporaneos. Unijui, Ijui, Portuguese, 2006: 183-191.

[49] Benesova O, Tejkalova H, Kristofikova Z, et al. Early postnatal diazepam treatment of rats and neuroimmunocompetence in adulhood and senescence. Annals of New York Academy of Sciences, 1994, 717: 89-101. 